Usage, Usability, and Utility of 3D City Models, 02004 (2012)

DOI: $10.1051 / 3 \mathrm{u} 3 \mathrm{~d} / 201202004$

(C) Owned by the authors, published by EDP Sciences, 2012

\title{
Interactive model of urban development in residential areas in Skopje
}

\author{
O. Marina ${ }^{1}$, E. Masala ${ }^{2}$, S. Pensa ${ }^{2}$ and M. Stavric ${ }^{3}$ \\ ${ }^{1}$ Faculty of Architecture, "University Sts. Cyril and Methodius" in Skopje, Macedonia \\ ${ }^{2} \mathrm{SiTI}$ - Higher Institute on Territorial Systems for Innovation, Torino, Italy \\ ${ }^{3}$ Institute of Architecture and new Media, Graz University of Technology, Graz, Austria
}

\begin{abstract}
Development of residential areas in Skopje in a period after the 1963 earthquake led to an emergence of continuous pressure to the physical structure of the city. It's essential to analyse, explore and understand the processes that are shaping our city. The study explores interactive tool that exercise the complex analysis of architectural and urban structure within the Skopje's residential areas and proposes a 3D model to investigate local dynamics and best fitting urban indicators for development. Through series of analysis of diverse typologies, programs, spatial and functional configurations of the dwelling within the city, the study presents an effort by use of Interactive Visualization Tool (InViTo) for modeling of urban development to explicate spatial distribution, the process of transformation and acknowledge the regularities and suitability of development of urban form in Skopje's residential area and, in particular, the relationship between functions and its localizations.
\end{abstract}

\section{INTRODUCTION}

In the last century and especially in the period of transition from socialism to capitalism the cities in South-Eastern Europe have experienced heavy transformation. In the context of a debate that examines these transformations, the continuities and the discontinuities in urban space, this paper focus on the development of 3D modelling tool for analysing and building knowledge on the urban change in residential areas of city of Skopje. It points out the importance of the tools for critical reading and understanding of city's past, research and comprehension of the dynamic city presence and support spatial decision-making and planning for the future urban development in residential areas.

There has been a profound change in what city represents, a deep restructuring of the meanings and spatial specificity and conceptual expression in the urban imaginary [1]. The apparent development of the Postmetropolis [2] has raised the notion of the human systems as systems that are far-fromequilibrium. Moreover, spatial aspect of human systems has become more complex due to technological change, bigger mobility and social, cultural and demographic transitions of these globalized processes.

Cities are complex systems constituted of physical elements interrelated in elaborated spatial relations. Its complexity is enhanced by its constantly changing and evolving shape and structure. To try to understand the dynamics and processes that are shaping our cities we have to develop models that are coherent with the dynamic and complex nature of the cities, but comprehensible and simple enough to be operationally useful. Hence, any attempt to model the spatial system and dynamics of the cities should involve this indeterminacy and instability of the cities and theoretical framework as one of its basic features. In the same time it should be followed with strong knowledge and data management that should provide necessary coherence with the nature of the city.

This is an Open Access article distributed under the terms of the Creative Commons Attribution License 2.0, which permits unrestricted use, distribution, and reproduction in any medium, provided the original work is properly cited. 
The main aim of this paper is to explore the process of urban transformation in the city of Skopje, with focus on the residential areas by simulating the development of residential urban area. The model of urban development is based on the spatial elements that influence its growth on the basis of distance with quantifiable effect, in order to be able to gather real data and translate them into geometry. For the model of urban development we use InViTo-Interactive Visualization Tool. InViTo makes use of parametric and generative features of Grasshopper for studying large areas and support their planning through interactive visualizations. It uses input data that can have different formats and is translated to a mathematical function that defines how it behaves in the space and determines its influence on each other elements.

First, the paper briefly reviews the basic approaches to the study of urban form and urban changes and the way that theory elucidates and elaborates the complex interaction between society and the city which is the core of our approach to modeling urban development. Our approach to urban modeling resembles a network perspective of a city as an interconnection of people, urban elements and their dynamic relationships.

Second, the morphological background of process of urban transformations is analyzed in attempt to understand the regularities of the process as an indicator of existence of dominant paradigm of this urban space and conceptual ground for a potential research of urban development of this area.

Third, after pointing out the divergence and convergence among all aspects and actors of urban change, the paper describes the case study of Taftalidze, one of the Skopje's residential areas using InViTo- an interactive visualization tool to depict the potential of urban development based on the functions of measured spatial elements and relation of functions within the urban area. Each of these spatial elements is related to a mathematical function in which distance is the variable. The geometrical result of those functions is an enriched 3D urban model in which the level of attractiveness of each spatial element varies depending on its distance. These functions are set on the basis of specific knowledge and performed survey among residents of Skopje.

Finally, the paper suggests the platform for spatial integration of the urban knowledge that enables us to understand the rules determining the effects on urban dynamics and to define which the acceptable values for new transformations are. The outcome of the model provides a comprehensible overview of the suitability of the residential function within the Taftalidze area of Skopje and can provide value on urban indexes and building size in relation to the determined parameters and desired urban form. Comprehension of the process and tendencies of the urban development in these areas will provide decision makers and researchers with independent source of knowledge and relevant information that could be used for understanding the spatial development of city of Skopje. It is an essential complement for the definition of strategies of city development. The results of the research will be used to challenge existing urban policies and in the same time to determine some new policies of future development of the city of Skopje.

\section{CITY AS A SPATIAL STRUCTURE}

Cities in general can be best recognized through their distinctive shape, complex organization and density of the build environment that they create. This environment is created through a construction of architectural objects with different morphology, functions, materiality and density. Its complexity and vastness of typology comes from a process of continuous creation of architectural and urban forms not only as physical objects but also as a process of creation of spatial, social and cultural relations. Through this spatial configurations system of urban form becomes the spatio-temporal manifestation of the order of the city realised through physical elements and urban morphology [3].

Process of production of urban space has often been attributed to the existence and influence of internal forces of the society and the dominant system. Following the thesis that space is a product of society [4], many theorists have claimed that the role of the process of production of urban space within the distinctive social order is to facilitate and further enhance the product of the dominant order while 
the overall authority secures the process [5]. In this notion, the dominant social order is a regulating force of the urban transformation with evident and clear spatial influence and formal consequences, while there is (almost) no part of urban life that exist outside the logic and rules of the dominant social order and the world-system [6]. The theories that see the dominant social order as a basic driving force of urban change more often limit our understanding of processes that are shaping our cities. The emphasis on the regularities of the social order with usual focus on economic parameters of urban change reduces or overlooks the multiplicity of actors, institutions, networks, structures, as generators of urban change, but most of all excludes the possibility of influence of urban structure to the overall process [5].

As an opposition to this deterministic notion of the relation of society with production of urban space is the idea that urban development is structured around a set of spatial relationships that evolve and emerge through complex interaction of the attractiveness and repulsion between the major land use and social infrastructure with the spatial characteristics of the build environment and the inherent urban structure of the cities [7]. These complex relationships transcend socio-economic conditions in the way that they operate to a large extent autonomously from shifts in economic and political policies and regimes [14]. The fact that people use the locality as site and resource for social activity realized in spatial manner in different ways reinforces the notion of existence of socio-sphere [8] as a complex social domain with overlapping networks and fragile balance between spatial behaviour and the urban environment. In order to determine the nature of this processes and in the course of building our case we can reflect on the model of spatial constituency of urban form [9], that is based on differences between the elements of the system. It is a result of a locally determined process of integration to a complex whole with a respect of the identity of the each distinctive element. Urban texture is generated through an emerging bottom-up process of interaction between the constituents and is recognized as a topological, irregular configuration. This structure is specific of the urban environments that have developed in spontaneous emergent process of morphogenesis of urban form. The greatest challenge of this observation of the cities as two distinctive systems-one social and one material, is to find the tools for exploration of relations and interdependence between them [4].

In attempt to overcome the deterministic notion of production of urban space as a result of predefined conditions and forces within the society and social order, this paper will investigate the tools of analysis and visualization as form of knowledge [10] of the process of urban change in residential area of city of Skopje. These tools are conceptualized more as a research worked through practice, a sort of open negotiation among different aspects of urban space and groups who act in accordance with their believes, motives and interest [5]. We should thus draw our attention to the ways that actors and institutions emerge and behave in spatial manner through time under specific conditions, an action that influences the production and change in urban space. Each of this activity is not an exclusive but rather a simultaneous process of interaction. Therefore, the process of urban change and resulting shapes cannot be determined as a static conditions of the urban form fixed in time, but rather a spatial and morphological result of otherwise dynamic phenomena of the city developed in process of coexistence and transformation. It is a bottom-up approach starting from the specific in the urban space, whether it is a building, its shape, a program or a person - the very elements within the system and goes through process of negotiation, a sort of dialog, toward the cooperation and cohesion in bigger entities, blocks, groups, neighbourhoods, trades, parts of the city and institutions, in which the 3D model should facilitate the interaction through providing a common basis for sharing the information.

\section{CRITERIA FOR EVALUATION OF URBAN DEVELOPMENT}

Urban form can be generally used to describe the city's physical elements and characteristics, or on a broader scale as a spatial configuration of fixed elements [11]. This concept of the urban form is scale 
sensitive and can be seen as a morphological attributes distributed along different scales [12] that results in a series of elements that range from very local and specific, like building materials and elements, through buildings and street types to the settlement layouts. Following the idea of the cities being interrelated systems comprised of material and immaterial aspects of the phenomenon, it is clear that urban form does not simple relate to the physical features but also encompasses non-physical aspects. Hence, there are non-physical economic, social and political processes which are physically manifested in the urban structure and urban elements of the city. Urban form can be generally determined as a number of physical features and non-physical characteristics including size, shape, scale, density, land uses, building types, urban block layout and distribution of green space [13]. These elements are interrelated and claimed to influence sustainability of urban environment and accordingly they are the basis for the criteria for evaluation of the urban development.

Most of these elements are complex concepts with number of inter-related dimensions, but they are also subject to objective, spatially-based measures in a given area. Although these measures of different aspects of the city are assessed subjectively, through social interpretation, and accordingly they may differ from a person to person [14], there are aspects of the city that can be evaluated with great level of confidence besides their subjective comprehension.

We approach these issues with the notion that at the very substance of the urban phenomenon is the enduring spatial relationships that create the complex but yet unified entity of the city. This spatial integration of differences in the urban contexts is the core in the structuring of the patterns and forces of urban development and growth [15]. These relationships are defined by the sources of spatial interaction, inter-dependence, attraction and repulsion existing between the major land use classes and elements of urban form. While this approach may provide basis for objective, spatially based analysis of the urban development it is also important to note that the evaluation indicators that address the dimensions of urban form, accessibility and spatial context are also coming from a different backgrounds and represent a very diverse set of evaluation tools with different principles, topics addressed and the outputs produced.

General urban development evaluation tool structure is based on the use of indicators grouped into categories to assess the suitability of urban design and development. It consists of five levels with increasing detail and specificity, from Sustainability dimension, through Design indicators, to Benchmarks as a reference values that the indicators need to meet or correspond to demanded quality level [16].

Having the focus of our research positioned on urban development of residential area in Skopje, being the part of the city clearly defines two of these levels for evaluation of urban development as most prominent and adequate. First level - Evaluation criteria - is the set of aspects of urban environment that need to be assessed in order to verify the response of the structure or change in the structure to the issue, e.g. access to public transport, access to local services, access to social infrastructure, schools, kindergartens and others. Second important level is Design indicators that represent the variables whose value is indicative of the performance of the design, with a unit and specific measurement method, e.g. percent of residents within specific walking distance of bus stop, average distance to the nearest green market, etc [16]. These two levels represent the critical transition in the process of comprehension and analysis of urban environment where decisions and assumptions have to be made in order to translate them from general concepts to more specific concepts and from theoretical concepts to empirical measures. Measuring the urban context through urban morphology and its spatial relationships is at the core of our approach in modelling urban development in residential areas in Skopje.

\section{MODELLING URBAN DEVELOPMENT}

\subsection{Urban context}

Development of city of Skopje is not a linear evolutionary path but rather a transitional leaps generating discontinuity and misbalance in planning policies as well as in realization of urban plans. This 
situation creates unique image of city of Skopje as a city-collage or more likely city-patchwork. Skopje's urban morphology is a result of discontinuous and unrelated urban concepts, planning policies and construction processes that were implemented or at least used as theoretical ground for urban development of the city. Most of these concepts disturbs the continuity of the development of the urban form and acts toward the urban context as a tabula rasa. Hence, as a result of this situation distinctive urban fragments are recognizable as traces of different phases of urban transformations and legacy of processes that are shaping the city of Skopje.

The most salient feature of the urban transformation and emergence of urban form in city of Skopje is differentiation on one side and coexistence of differences on the other. Urban transformations were on one hand path-dependant, as an outcome of specific historical and geo-political factors, while on the other hand rested on the actions and emergent forms of interaction between the actors in urban space, local dynamics and urban concepts. This complex network of relations between different actors, institutions, rules and restrictions, society and individuals, market and society, buildings and urban blocks, urban and suburban, city and nature is a very substance of the process of urban transformations based on negotiations and urban dialog between the users and elements of urban space. This is its distinctive quality and a basic driving force behind the emergence of urban form and urban change.

This situation urges for establishing knowledge-based operative approach that will provide the spatial integration of different aspect of the urban context and will link these fragments into a liveable whole through the comprehensive tool for the analysis of urban development.

\subsection{Model of urban development}

Models of urban development have been present in the research of urban phenomenon for more than a half a century. The idea that a complex system such as city can be translated into a simplified form with high level of abstraction was used in order to obtain a tool for controlled exploration of the systems associated with cities. The early models were condemned as "too simple" or "too complex" to successfully grasp with the complex task of providing useful tool for better understanding the cities. Their existence has been justified with the notion that the complexity of the studied phenomenon or system could be matched only through models that are complex enough and through it to provide the accurate level of details requested by the policy-makers. As an opposition to this trend is a tendency and urge to develop city models that are simpler than the former but that are inherently open toward producing more complex result based on simple spatial rules and interactions [17].

This model should serve as a spatial integration of distinctive urban knowledge and the spatiality and formality of the city. It should explore and represent forces and processes that are beyond materiality of urban form and reveal the hidden aspects of processes of urban change. It should contain tools for exploration and analysis of the city form, but in the same time to be able to depict risks and opportunities for future conditions. This suggests that the observation of the future conditions of the city gained as a product of the model should be at least ordered and structured as any observation of the system in the past or present in order to provide a consistent support to new planning projects.

The model of an urban form that we have developed should map the dynamic behaviour of the urban form in city of Skopje residential areas. That is, to be able not only to map the fixed position of elements of the urban form in time, but rather to have the potential to define the way elements of urban form change in time and their development is determined by their spatial inter-relations. Only in that case the model of urban form would not be related to fixed and stable conditions of elements, but would refer more to the dynamics of development, change and adaptations of the system. The benefit of this approach is that the elements and the relations of the model representing the development of the urban form system would emerge exclusively as locally determined and decentralised process of complex order creation. It will enable us to comprehend urban development as a continuous process of changes in policies, normative constraints, citizen needs, spatial, economical and social relationships. 
Usage, Usability, and Utility of 3D City Models

\subsection{Methodology}

Urban morphology can be investigated in different ways. Traditional methodologies provides studies mostly based on professionals' experience, but the use of computer analysis presents a wide range of opportunities in defining approaches, methods and tasks. The research described in this paper focuses on approaching urban morphology by the use of a three-dimensional model which relates the suitability of places with their shape, distances from the other functions, infrastructure and facilities, in order to provide knowledge and awareness on local dynamics.

The chosen approach makes use of an Interactive Visualization Tool (InViTo), which is a methodological system based on "Grasshopper", a free plug-in of McNeel's "Rhinoceros" software. It makes uses also of Microsoft Excel and it can be integrated by scripts in Visual Basic language. It generates parametric shapes that can change in real time through an interactive interface, which allows users to modify values and rules of the model. InVito can use different kind of inputs such as GIS data, databases, raster and vector files allowing high compatibility with the largest number of software generally used by technicians involved in planning processes. InViTo organizes these input data in a flow framework which link the spatial elements with a specific behaviour. Since each element generates an attractive or repulsive influence on the behaviour of the other elements, it provides in real time a visual outcome of relationships among choices and spatial effects. In this way, planners and, more generally, decision makers can directly evaluate their large scale choices as effects on small scale areas, improving their perception and knowledge on urban dynamics.

Thanks to this visual interactive framework, by which users can work in real time with information, InViTo is well suited to be used during focus groups, workshops, meetings and public debates. For this purpose, it offers a wide range of visual outputs which can be previously decided in order to better meet the target of audience and level of expertise of the actors involved in the debate. The tool outputs can be set as both 2D and 3D representations, which can have a photo-realistic as well as symbolic aspect. However, to deal with expert public, InViTo is used with symbolic visualization to better support the analysis of the concepts behind the spatial design. Then, outputs as dynamic maps or volumetric diagrams are preferred to show the spatial whole ensemble as well as highlight the behaviour of single elements or clusters of elements at both micro and macro scale.

\section{SKOPJE CASE STUDY}

\subsection{Urban Morphology}

Development of Taftalidze residential area in Skopje is a product of the process of reconstruction and renewal of the city of Skopje after the devastating earthquake in 1963 that have left the city with more than $85 \%$ of building stock ruined or with high level of devastation [18]. Urgency in the post disaster management of the city accompanied with the great demand for housing in a very short time period has created a situation where new residential areas in city of Skopje were developed. Taftalidze residential area was part of this process of urbanization of the metropolitan area of the city beyond the existing, at that time, city limits. At the conceptual level this residential area is defined by the orthogonal street network and distinctive zoning of functions within the area.

Detached and semi-detached houses were the favoured types of houses clustered in the green areas. Street network, parcels and buildings will be positioned within the area without any reference or relation to the existing topography, existing urban structure or spatial experience of the city. This conceptual and formal matrix will be a base for development of this residential area in the next forty years during which the conceptual and real transformations of the city of Skopje and its expansion and growth will be evident within the structure and shape of the residential area.

Urban transformation of the urban structure of Taftalidze residential area can be defined at two main levels. First level is the level of external urban transformations that are shifting the relationship between the city and the residential urban structure. Changes in the city, its expansion and growth, urban planning 
codes, increased mobility, growing demand for urban services, radical changes of the demographic, social, economic and cultural structure of the city have generated whole set of external influences on the transformation of the structure of the city and the specific area. They relate to the changes in the morphology of the elements of the city in general and to the changes of the land use, functions and programs of the city. Second level of urban transformations is situated within the inner structure of the residential area. These transformations are affecting the structure and spatial relationships within the area. These transformations are determined as morphological and functional and mostly are interdependant. They are manifested though the changes in a scale ranging from the discrete building or a parcel to the level of the changes of spatial relationships between these elements.

Frequent shifts in the social and economic context of the city of Skopje followed by distinctive changes in population are followed with different level of transformation within the urban structure and architectural morphology of the residential area. These differences between external and internal forces have created productive tension that generates highly vibrant and dynamic urban morphology of the Taftalidze residential area. InViTo has been used to explore and to define potential as well as the localization of most suitable areas for future urban transformations and development within the Taftalidze area for the residential choice.

\subsection{The indicators}

The criteria for establishing indicators of suitability or attractiveness of distinctive elements of urban form and their spatial inter-relationships within the residential area have been determined through a research survey. Research has been performed as an anonymous survey with questionnaire among the general population in Skopje with target group of population of age between 35-44 years and with representative sample of $45 \%$ male and $55 \%$ female out of total of 209 survey participants.

First group of questions (1-4) were targeting the following issues:

- Level of attractiveness of the specific residential areas,

- Importance of the different criteria for evaluation of the residential area

- Importance of the selection of the residential area during the process of selection of real estate. Second group of questions (5-10) has been measuring the level of comfort related to the distance from the place of residence to the urban infrastructure (boulevard, cross-section, bus stop, park, industrial facility, and city centre).

Third group of questions (11-13) has been measuring the level of comfort related to the distance from the place of residence to the commercial infrastructure (grocery shop, shopping centre, green market).

Fourth group of questions (14-18) has been measuring the level of comfort related to the distance from the place of residence to the social/civic infrastructure (kindergarten, elementary school, medical facility, and pharmacy and sport centre) that is present in the residential area.

Fifth group of questions is exploring the preferences regarding the following:

- Typology of the residential building (house, building with less than 8 apartments, building with more than 8 apartments and residential high rise)

- The size of desired backyard/garden as a part of the parcel where the residence is located.

- Typology of the program (use) of the building of the residence.

Participants in the survey had been guided to answer all the questions with values (numbers) ranging from 1 to 5 where 1 is the less appropriate option and 5 the most appropriate one. They had an opportunity to fill all the options or just to state the min. (1) and the max (5) without evaluating all the options.

\subsection{The setting of spatial dynamics}

The survey concerns the whole city of Skopje, but the 3D model has been used to analyse only the Taftalidze area which results, from question n. 1, the most attractive of the city. For the same reason, 
Usage, Usability, and Utility of 3D City Models

Table 1. Weights value among the curves.

\begin{tabular}{|l|l|l|}
\hline i & Parameters & Weight $(\beta)$ \\
\hline 1 & Distance to the park / green area & 3.16 \\
\hline 2 & Distance to the kindergarten/school & 4.00 \\
\hline 3 & Distance to the shopping centre & 2.20 \\
\hline 4 & Distance to the sport centre & 2.66 \\
\hline 5 & Good urban traffic infrastructure & 4.50 \\
\hline 6 & Good public transport & 3.33 \\
\hline
\end{tabular}

not all the elements investigated by the survey have been used. Considering only the Taftalidze area, the distance to the city centre is assumed as almost the same in the whole area, while the services as electricity, heating and waters supply are considered as available. Then, the parameters used in the model are the following listed in the table below.

The model works on Utility equation that is how much a specific element deals with a specific location, allowing both positive and negative values.

$$
U=u\left(x_{1}, x_{2}, x_{3}, x_{4}, x_{5}, x_{6}\right) .
$$

Data gathered by the survey has been used to set the dynamics of the model. The second, third and fourth set of questions on urban, commercial and social infrastructure (5-18) defined the level of suitability in relation to the distance $\left(S_{i}\right)$, measured in meters or walking time, from the residential building.

Once each of these parameters has been assigned to its relative spatial elements on a map, the model needs to weight how much each parameter contributes to define the suitability. To define the weights $(\beta)$ of importance among the different spatial elements, the model uses the outcomes of a specific question (n.3) of the survey in which people was asked to weight each parameter for choosing their favourite residential area. The suitability of each point results from the weighted sum of all considered parameters (i) as follows:

$$
S_{t o t}=\sum \beta_{i}^{*} S_{i}
$$

$S=$ suitability

$\beta=$ weight of each parameter (i).

This function combines the effects of all considered parameters, providing a way to define the most important spatial elements which affect the residential location.

For allowing users to explore the model, all weight indicators $(\beta)$ can be modified by actors involved in planning process in order to see and evaluate the effect on spatial distribution of residential units. Roads, bus stops as well as specific building as shop centres or schools can be relocated, for instance for simulate a project option, so that new possible alternatives can be evaluated. The model provides responses in real time, so users can interact with information and spatial effects obtaining a high degree of knowledge on questions to be solved.

\subsection{The results}

The outcome of the model generates different maps of suitability for each considered spatial elements as well as for each combination of elements (Figure 1).

These maps provide localized values of suitability, thus highlighting the areas with more and less attractiveness. Overlapping all the maps together, it is possible to delimitate the areas that, whatever indicator is considered, are in any case more or less suitable.

This result provides important information, especially for planners in charge of re-design the area. First of all, it is interesting that all maps agree on bordering specific areas for both highest and lowest 


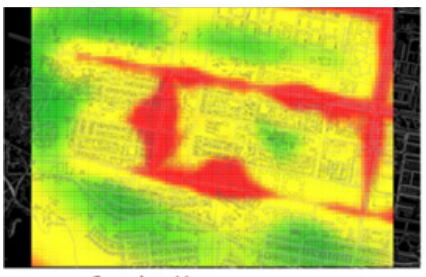

Complete Map

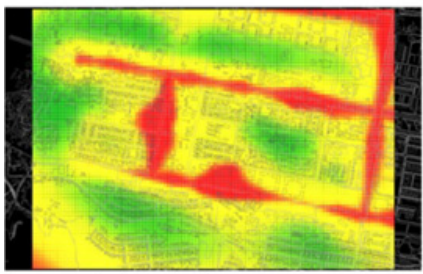

No Shopping Center

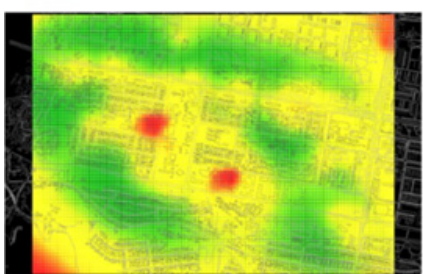

No Boulevard and Shopping Center

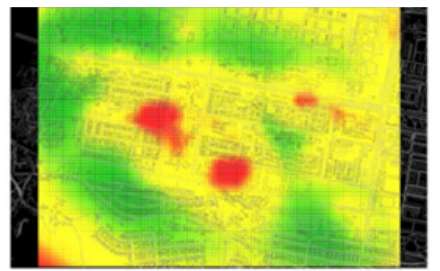

No Boulevard

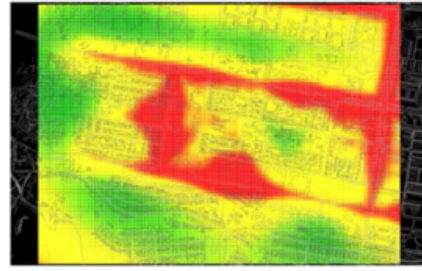

No Bus Stops

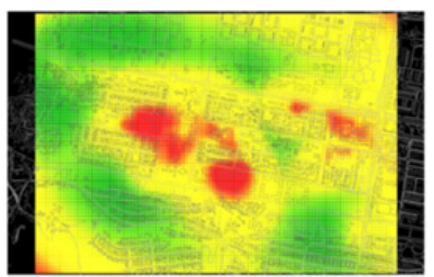

No Boulevard and Bus Stop

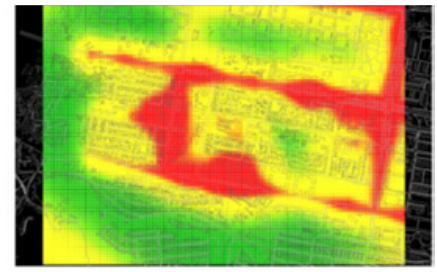

No Local Stores

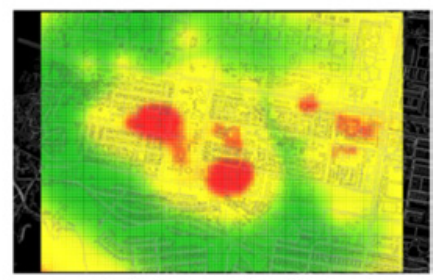

No Boulevard and Local Stores

More suitable

Less suitable

Figure 1. Suitability considering different spatial elements.
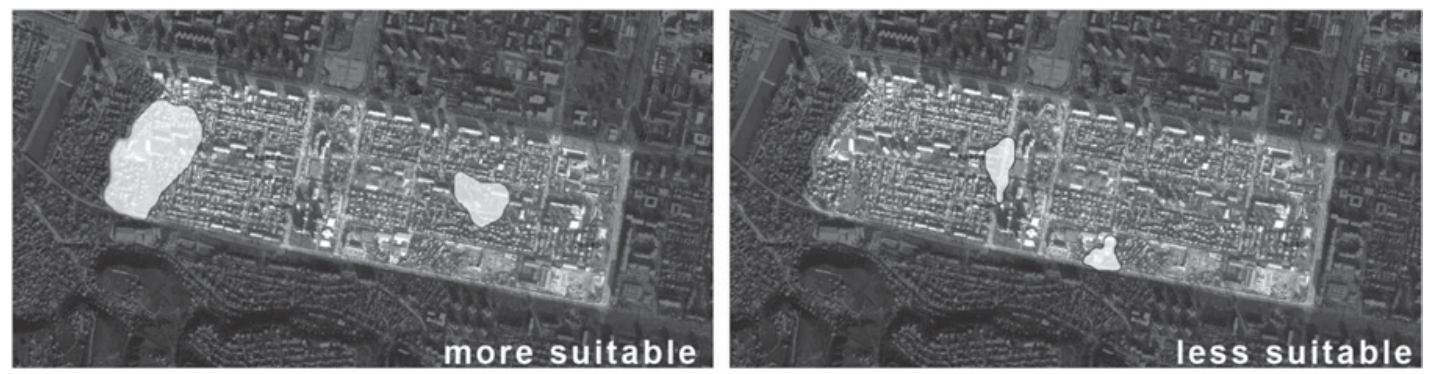

Figure 2. More suitable (on the left side) and less suitable (on the right side) zones for the considered spatial elements in Taftalidze area of Skopje.

values of suitability. This shows a robust attitude of these areas in relating to the residential function. Secondly, considering the localization of both more and less suitable areas, it appears evident that people prefers a residential location in a mono-functional area, with a relative but consistent distance from urban facilities and infrastructures.

Stores, shopping centres, bus stops, boulevards as well as kindergartens, schools and sport centres are perceived as necessary but disturbing residential activities. This is particularly evident in the map about less suitable areas, where the middle-central zone, which includes many urban facilities, results as bad dealing with residential function. Thirdly, the presence of boulevards largely affects the residential suitability and this certainly requires a specific reasoning by planners on the use and attractiveness of city boulevards. Another element that negatively affects residential functions is the presence of shopping centres, which is highly perceived as a trouble. The low influence of bus stops as public transport facility 


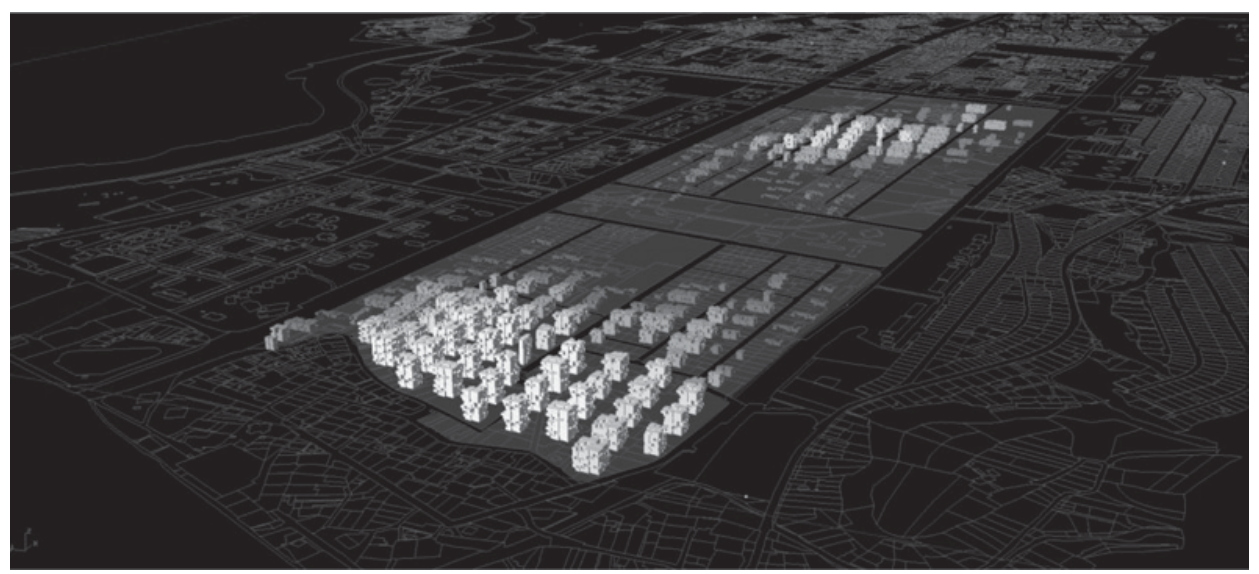

Figure 3. Distribution of suitability in Taftalidze area of Skopje, where white volumes indicate the most suitable areas.

shows the importance of private transport mode and, indirectly, justifies the necessity to have a house or apartment distant from City Boulevard.

Beyond these results, what is of considerable importance is that InViTo allows users to interact with all these parameters, providing a framework for organizing the urban knowledge into a perspective of cooperation among actors coming from different disciplines and with various expertise. In this sense, the $3 \mathrm{D}$ model shows to be more effective than $2 \mathrm{D}$ visualization because is able to generate a pre-figuration of how quantitative values, as urban indicators give, can be translated in urban form. In particular, it is very important for allowing users to play with indicators and see their spatial effect on different project/planning options.

\subsection{The 3D morphological quest}

The outcome of the model provides a map which describes how much is suitable the residential function in the Taftalidze area of Skopje. This data can be expressed in a 3D map as a volume, which has been divided into several spatial units (Figure 3).

The volume of the newly established 3D shapes has been set depending on suitability level. The volumes related to the highest value of suitability have been set in order to cover an area of maximum $20 \mathrm{~m} \times 20 \mathrm{~m}$ and to have a height of maximum $21 \mathrm{~m}$. In the meanwhile, the volumes related to the lowest value have as constraint to be high as just one floor and to cover an area large $10 \mathrm{~m}$. Then, volumes have been divided into single apartments through an add-on of Grasshopper, which allow filling a volume with pre-defined smaller volumes. In this way the tool has automatically generated building with hypothetical spatial elements, with variable size from 40 to $150 \mathrm{~m}^{2}$ that are located in block or houses depending on level of suitability.

This 3D model is not just the visualization of the attributes of fixed urban elements, but rather an emergent shape resulting from complex interaction of spatial relationships between social and urban structure of the city. It gives a possibility of developing a complex interaction between the chosen parameters of the urban environment that result with production of new and previously untraceable, due to its complexity, urban knowledge.

The development of parametrically dependant model of suitability and attractiveness of the Taftalidze residential area in Skopje should provide a platform for spatial integration of urban knowledge. The spatial analysis and visualization of chosen parameters that we have performed on the data gained from the survey is a powerful tool that should enable decision makers and citizens 
to enhance their participation in the process of planning and development of the city though better understanding and comprehension of the 3D aspects of the city and spatial consequences of the policies for development. It is a necessary step toward developing a more elaborated city model that will introduce spatial interaction of architectural morphology on a more substantial level and that will bring 3D aspects as an unconditional tool for better understanding of cities. It could be reached only through a city model that recognizes and is coherent with the multidimensional nature of the cities.

\section{CONCLUSIONS}

3D modeling of urban development appears as an effective tool in approaching urban planning for several reasons. First of all, parametrically determined city models can provide comprehensive tool for analysing development scenarios and design solution with a very large number of elements to consider. Secondly, it can quickly provide localization and spatial emergence of different urban aspects, helping practitioners in their reasoning and enabling policy makers to promote real time debate with the local communities securing the citizen participation during the planning process.

The complexity of the result comes from a locally driven set of simple rules that induce continuous adaptations and changes on local level but with an impact on the overall condition of the system. It provides us with the tool that can generate complex and novel shapes and configurations as a result of a dynamic, nonlinear and locally driven process. These new structures are more than a sum of their parts and are not predetermined or preconceived by any means. In particular, the use of an interactive tool such as InViTo allows users to combine different solutions and to receive in real time a feedback on the localization of the effects of their specific choices.

It enable us to fulfil the imperative of this research project to become the milieu of a confrontation among the economic, social and spatial aspects involved in the city's transformation processes and to provide the public administration, institutions or private sector companies with a tool for morphologic consultancy service on operations of greater complexity and relevance concerning the city. It will provide insight into the process of morphogenesis, better understanding of phenomenon of cities, and an opportunity for better understanding of potential for sustainable future development, but above all better understanding of results and consequences of our actions into the world that we live in.

\section{References}

[1] M. Batty, Vis-driv. urb. sim.: Expl. fast and slow ch. in res. Lon., CASA, work. pap. ser., n.164, 03/2011, UCL, Lon (2011)

[2] E.W. Soja, Postmetropolis: Crit. Studies of Cities and Regions, Blackwell Publishing, Oxford (2009)

[3] B. Hillier, J. Hanson, Space is the Machine-A Configurational Theory of Architecture. Cambridge University Press (1996)

[4] H. Lefebvre. The specificity of the city. In E. Kofman, E. Lebas, Writings on cities, Cambridge, England: Blackwell (1996)

[5] A. Orum, Chen, X. The World of Cities. Places in Comparative and Historical Perspective, Oxford: Blackwell (2003)

[6] S. Sassen, "New Frontiers Facing Urban Sociology at the Millennium", in British Journal of Sociology. 51 (2000)

[7] D. North, Institutions, institutional change and economic performance, Cambridge: Cambridge University Press (1990)

[8] M. Albrow, Travelling beyond local cultures: sociospaces in a global city, In; Eade, J.(ed) Living the Global City. London: Routledge (2000)

[9] E. Durkheim, On Division of Labor Society, The Free Press, New York (1964) 
[10] MacEachren, A. (2004). Geovisualization for knowledge construction and decision-support. GeoVISTA Center and Department of Geography, the Pennsylvania State University

[11] W.P. Anderson, Kanargoglou, P.S., and Miller, E. Urban Form Energy and the Environment: A Review of Issues, Evidence and Policy. Urban Studies, 33, pp. 17-35 (1996)

[12] K. Williams, Burton, E. and Jenks, M. (eds.) Achieving Sustainable Urban Form. E \& FN Spon, London (2000)

[13] N. Dempsey, Brown, C. Raman, S. Porta, S. Jenks. M, Jones. C, Bramley. G, Elements of Urban Form, in Jenks. M, Jones. C, Dimensions of the Sustainable Cities, Springer, London, pp. 21-51 (2010)

[14] A. Churchman, Disentagling the Concept of Density. Journal of Planning Literature, 13(4), pp. 389-411 (1999)

[15] K. Stanilov, Batty, M. Exploring the Historical Determinants of Urban Growth Patterns through Cellular Automata, Transactions in GIS, 15(3): pp. 253-271 (2011)

[16] S. Curwell, Deakin, M. Symes, M. Sustainable Urban Development: Protocols and Environmental Assessment methods v. $11^{\text {st }}$ ed., Routledge (2005)

[17] M. Batty, A Generic Framework for Computational Spatial Modelling, CASA, work. Pap. Ser., n. 166, 05/2011, UCL, London (2011)

[18] UNDP, Skopje Resurgent: the story of a United Nations special fund town planning project, New York, United Nations (1970) 